\title{
Visar a perfeição para atingir a beleza
}

\author{
Deolinda Catarina França de Vilhena
}

"Não existe arte sem esforço. Somente visando a perfeição é possível atingir a beleza" (Mnouchkine, 1991).

irigido por Ariane Mnouchkine, o Théâtre du Soleil pode se orgulhar de ser a única companhia de teatro francesa em atividade ininterrupta há exatos quarenta anos, exceção feita à Comédie-Française. Precursora e não herdeira do movimento de Maio de 68 , nela não existe a figura do primeiro ator e a divisão de tarefas é cláusula de um contrato de honra, com que trabalham 84 pessoas, recebendo todas o mesmo salário.

Ao longo de sua trajetória, a companhia criou vinte e cinco espetáculos, alcançou reconhecimento internacional, superou a marca de dois milhōes de espectadores e se apresentou, em língua francesa, em países tão diferentes quanto Alemanha, Japão, Estados Unidos, Israel, Austrália e Canadá. A trupe de Mnouchkine revolucionou a cena teatral a ponto de ser considerada por Denis Bablet a maior aventura do teatro francês depois do Teatro Nacional Popular de Jean Vilar. O teatro francês, na segunda metade do século XX, pode ser dividido em antes e depois de 1789, trabalho inaugural do Théâtre du Soleil.

Entretanto, as especificidades dessa trupe começam já em 1964, quando da escolha do estatuto jurídico da companhia. Mnouchkine opta pela criação de uma Sociedade Cooperativa Operária de Produção (SCOP), empresa coletiva baseada na associação voluntária de pessoas dispostas a exercer uma atividade econômica que respondesse às necessidades do grupo, cuja gestão passa a ser feita por todos os membros e os lucros divididos eqüitativamente. A vontade de fazer um teatro diferente passa, logicamente, pela busca de novas formas de organização econômica e social e pelo questionamento do modelo capitalista. Afinal, para Mnouchkine não se pode separar o teatro da forma como ele é produzido.

Mas isso seria apenas o começo. David Bradby há anos chamou a atenção para essas revoluçôes que passaram pelo questionamento do estatuto do texto, do papel dos diversos membros da companhia, da forma do espaço de representação, da relação ator/espectador, sem esquecer de dizer que o Soleil conheceu uma seqüência de sucessos populares, apesar de sua atitude resolutamente experimental e da insta-

Deolinda Catarina França de Vilhena é pesquisadora, doutoranda do Instituto de Estudos Teatrais da Universidade Paris III. 
lação numa fábrica de munição do exército francês, num subúrbio pouco chique da capital francesa (cf. Bradby, 1990).

Empenhada em "restituir a beleza ao espetáculo cênico" (Neuschaffer, s./d.), como pregava Jacques Copeau, Mnouchkine busca uma forma teatral pura, fazendo um teatro ao mesmo tempo elitista e popular, em que a dialética da criação implica na aventura proporcionada pelo trabalho coletivo, mas também na necessidade de alimento e aprendizagem, oferecida pela confrontação com os grandes textos. Para alcançar seus objetivos, Mnouchkine não abre mão do seu principal instrumento de trabalho, a trupe, que conduz a um processo coletivo de criação, e também da política de fazer do Théâtre du Soleil um teatro que reflita a sua época, a exemplo dos gregos, de Shakespeare e de Molière.

Cada espetáculo criado no Théâtre du Soleil é fruto de intensa pesquisa e de um permanente questionamento de cada membro do grupo. Essa mesma pesquisa levou a companhia, entre 1968 e 1975, momento em que privilegiava a criação coletiva, a ter como referência a commedia dell'arte, que mais tarde cederá lugar às influências orientais - nô e kabuki - e ao encontro com o teatro shakespeariano, no início dos anos 80, e com os clássicos gregos nos anos 90.

Trabalhando a partir de textos dramáticos existentes, o Théâtre du Soleil criou o seu próprio sistema de referências, dando uma coerência formal aos espetáculos, empurrando a escrita teatral para novas dimensôes simbólicas e metafóricas da realidade e reencontrando, no presente, a aura mística e sagrada perdida ao longo do processo de civilização, e que Mnouchkine foi buscar no Oriente:

"O que me interessa na tradição oriental é que o ator é um criador de metáforas. Sua arte consiste em demonstrar a paixão, em contar o interior do ser humano, e também as histórias. Enquanto no Ocidente ensinamos os atores a cerrar o maxilar e a não demonstrar o que se passa. (...) Quando decidi- mos montar Shakespeare, o recurso oriental apresentou-se como uma necessidade. Talvez porque Shakespeare se situe na metáfora das verdades humanas. Procuramos, por conseguinte, a maneira de levá-lo à cena evitando o realismo e a banalidade" (Mnouchkine, 1984a).

Com Hélène Cixous o Théâtre du Soleil encontra-se, pela primeira vez, na situação de trabalhar com um autor que escreve para o grupo e cria com ele, estabelecendo uma perfeita simbiose. A chegada da autora marca uma nova orientação nos caminhos da companhia, até então mais voltados para as tragédias do presente, e também influencia seu ritual de representação. A dramaturga acredita que a distância histórica oferece mais elementos ao imaginário dos atores do que a época contemporânea, ainda relutante em dar lugar a uma paisagem estável, passível de ser depositada no inconsciente de cada um.

Nessa procura de um caminho próprio, o Théâtre du Soleil não perde a possibilidade de lançar um olhar para o passado. É graças a esse olhar que a trupe de Mnouchkine cria um teatro novo sobre fundações absolutamente intactas, partindo das formas tradicionais para construir outras novas e revolucionárias, como foi o caso em Tambours sur la digue, espetáculo influenciado pelo bunraku e considerado por Georges Banu a obra-prima de Mnouchkine. Redescobrir no longínquo o que é próximo e olhá-lo com admiração, tal é a transformação que Cixous e Mnouchkine impóem ao distanciamento brechtiano. Como em Brecht, esse distanciamento age com um objetivo didático ou mesmo ideológico. Mas se para Brecht tratavase de decifrar os mecanismos sociais a fim de tornar a sociedade mais justa, no Théâtre du Soleil o que importa é a análise do ser humano que, imerso na civilização materialista ocidental, perdeu suas raízes espirituais, e nesse domínio tem muito a aprender com a Índia e a Ásia, por exemplo. Cansada do realismo ocidental, Mnouchkine prospecta as fontes do teatro ori- 
ental em busca de algo que alimente sua capacidade de imaginação:

\begin{abstract}
"O palco de um teatro é um vazio muito bonito. O que é que o preenche? Não é o cenário. É a imaginação dos espectadores solicitada pelos atores. Nós, ocidentais, criamos apenas formas realistas. Isto quer dizer que nós não criamos uma forma propriamente dita. No momento em que usamos a palavra forma, quando se fala de teatro, já aparece uma noção oriental. E o que nós buscamos, sempre, é uma forma” (Mnouchkine, 1984a).
\end{abstract}

\section{Le dernier caravansérail}

Se em todos os teatros da França um espetáculo é criado, em média, em cinco semanas, no Théâtre du Soleil esse tempo pode ser de um, dois ou três anos, único luxo da trupe de Mnouchkine. Como diz Richard Monod, "o Soleil é um grupo que se dá o tempo de amadurecimento e que, trabalhando sobre si mesmo, vive pobremente para fabricar espetáculos ricos" (Monod, 1997). Mnouchkine se justifica:

"Eu sou lenta, eu não tenho a arte infusa, eu devo procurar para encontrar. E existem na trupe jovens atores que precisam trabalhar. 'O tempo se vinga sempre daquilo que fazemos sem ele', no teatro mais do que em qualquer outro lugar. Eu trabalho como uma condenada porque eu sei que, sem isso, o resultado não será bom. Se você quer 'encantar' o público, no sentido nobre do termo, incantare, durante seis horas, é preciso trabalhar até o limite das suas forças. Se você não fizer assim, você é um covarde, um traidor, um impostor" (Mnouchkine, 2004b).
Le Dernier caravansérail - Odyssées ${ }^{1}(O$ último caravançarai - Odisséias), mais recente criação de Mnouchkine e, na opinião da própria encenadora, um dos mais importantes espetáculos da trupe, é fruto de um processo de maturação de quinze meses. Com três horas de duração, Le fleuve cruel ( $O$ rio cruel), subtítulo da peça, é apenas a primeira parte de um trabalho ainda em processo de elaboração, que será completado, posteriormente, com uma segunda parte, intitulada Origines et destins (Origens e destinos).

No espetáculo, Mnouchkine retoma, mais uma vez, sua estrada de referência em direção ao oriente, a caderneta em uma mão e o gravador em outra. Lembrando-se, certamente, de seu próprio pai, vindo da Rússia, que durante a juventude conheceu as dificuldades do exílio, Mnouchkine ouviu, durante dois anos, os que fugiam do insuportável, gravando as conversas e recolhendo material para dois ou três espetáculos. Por meio da escuta de línguas particularmente bonitas, poéticas e figuradas como o persa e o curdo, cuidadosamente traduzidas, Ariane registrou muitos testemunhos nos diversos campos que visitou, relatos misturando vidas, viagens e aventuras que reuniu, mais tarde, numa estrutura polifônica. Acompanhada pelos atores Sarkaw Gorany, um iraquiano curdo que passou pelo Irã, pela Turquia, pela Grécia e pela Itália, permanecendo três semanas como refugiado em Sangatte antes de encontrála, e Shaghayegh Beheshti, ou simplesmente Shasha, também iraniana, nascida em uma família de poetas, que mora há anos na França, ambos servindo de intérpretes, Mnouchkine completa sua ampla pesquisa com os refugiados.

De onde vêm esses refugiados? Muitos vêm do Oriente Médio, do Afeganistão, do Irã, do Iraque, do Curdistão, dos países da Europa

1 Odisséias, título inicialmente previsto por Mnouchkine, em função dos relatos épicos e poéticos que narram as aventuras desses refugiados. 
do leste, de Moscou. Para onde vão? As viagens são feitas em direção à Austrália, à Europa, passando por campos como os de Sangatte, parada obrigatória para os que procuram chegar à Inglaterra. Comentando as entrevistas que realizou, Ariane observa:

"No começo, eles emitiam uma opinião his-
tórica, política. E progressivamente, chega-
vam ao vivido, ao dia a dia. Houve relatos
magníficos e outros insignificantes. Principal-
mente os dos homens, ainda que as mulheres
tenham mais motivos para querer partir, e as
que conseguem são realmente 'titanescas'.
Além do mais, esses deslocamentos atingem
tanto os pobres quanto os ricos, os cultos e
os ignorantes, os crápulas, etc." (Mnouchkine,
2003b).

Impressionada, inicialmente, pelas histórias de amor vividas durante a fuga, que separavam amantes ou marcavam reencontros, e depois pela maneira como eram contadas, Mnouchkine interessou-se, acima de tudo, pela dureza dessas viagens e pensou nas grandes narrativas gregas como a Odisséia ou ainda nos relatos infinitos das Mil e uma noites. Só depois veio a idéia do caravançarai. Os caravançarais são originalmente os lugares onde as caravanas descansam por um tempo bastante curto, uma noite, às vezes dois ou três dias, para que os viajantes descansem. Tempo usado para a troca de informações sobre as viagens e as últimas notícias sobre as "passagens". Por ocasião dessa troca de informaçôes e de comércio, acontecem inevitáveis encontros unindo dor, canto e poesia.

É claro que todos os envolvidos no trabalho sabiam que essas viagens eram terríveis, mas ninguém avaliava exatamente o que cada uma delas significava. Seguindo os que conseguiram escapar do inferno e ouvindo as pessoas que os ajudavam, acolhiam ou matavam, Mnouchkine reuniu centenas de horas de gravação, que formaram a base do material inicial de Le Dernier caravansérail:
"Eu falei longamente dessas viagens, desses encontros e dessas entrevistas aos atores do grupo, mas não deixei que eles ouvissem as gravaçôes. Eu queria que eles usassem a própria imaginação, a capacidade de médium porque os atores são médiuns -, e que esta capacidade pudesse estar totalmente livre, o maior tempo possível. Eles começaram por imaginar as situações. As gravações vieram apenas comprovar que eles estavam prontos. O espetáculo veio em pedaços e não em ordem cronológica" (Mnouchkine, 2003a).

Mas como mostrar no palco o drama dos refugiados? Como falar do exílio forçado, da guerra, da dor? Da maneira mais simples do mundo: fazendo falar os próprios refugiados, cumprindo a promessa feita de testemunhar ao mundo a história deles, como lembra Mnouchkine a seus atores:

"A grande responsabilidade de vocês é de respeitar a promessa feita àqueles que nos contaram suas histórias. Não podemos traí-los. Nos personagens de vocês existe um ser humano que continua vivo em algum lugar" (Mnouchkine, 2004c).

Durante o processo de trabalho, durante o verão de 2002, Mnouchkine realizou um dos seus famosos estágios. Como se sabe, no Soleil os estágios substituem o peso de uma escola permanente. Para Mnouchkine, a escola é um laboratório aplicado ao espetáculo em curso, que evoluirá naturalmente durante as representaçôes diante do público. Para descrever cada começo de trabalho, a diretora usa a metáfora da página em branco, como que para sublinhar a intenção de agir sem idéias pré-concebidas: tudo deve ser submetido à prova do palco, inclusive as experiências anteriormente adquiridas, com o objetivo de testar o "prazo de validade".

Como no Théâtre du Soleil não existem as leituras de mesa, cedo os atores estão no palco para improvisar, procurando ajudar-se por 
meio de elementos como máscaras e figurinos. Também não existe a distribuição de personagens. Durante os ensaios, os atores interpretam os personagens que desejam, pois a conquista do personagem é fruto do trabalho diário, em que cada ator aproveita as descobertas dos outros para um mesmo personagem, num trabalho que age no sentido do exterior para o interior. Duccio Bellugi-Vannucini, há dezesseis anos ator da companhia, conta como foi feito o trabalho durante os ensaios de Le Dernier caravansérail:

\begin{abstract}
"Trabalhamos sobre improvisações a partir de situaçôes oferecidas. Um número infinito de improvisaçōes. Conservamos primeiro umas 150 , depois 100 . Tudo era fotografado e gravado em vídeo, para que não perdêssemos as pistas desse enorme trabalho. Os freqüentadores assíduos do Soleil podem esperar por surpresas. Existe pouco texto. Mesmo a interpretação vai surpreender. Ariane renovouse completamente. Era bonito vê-la dirigir uma coisa extraordinariamente diferente" (Beluggi-Vannucini, s./d.).
\end{abstract}

O espetáculo é composto de diferentes cenas, passadas sobre elementos móveis que utilizam apenas uma parte do palco, como se os refugiados estivessem perdidos no vazio. Nenhum dos personagens, imigrante ou não, toca o chão, pois todos deslizam sobre carrinhos de rolimã, empurrados por outros atores. É uma maneira de lembrar que o drama desses fugitivos, sem direito a escolher seu destino, é universal. Como nota Ariane:

"É o trabalho mais coletivo jamais feito no Théâtre du Soleil! Nós podemos dizer hoje que, no nosso palco, há um elemento infinitamente pequeno, porque existe um infinitamente grande. Se queríamos falar do mundo inteiro, era preciso falar de todos esses pequenos universos. Dei como instrumento de trabalho o princípio do carrinho de rolimã, que acabou desencadeando e permitindo tudo. Eu não queria que os atores andassem em cena, disse não ao passo! Os espectadores hoje encontram as mais belas explicaçôes para o uso desses carrinhos, mas eles foram antes de tudo uma necessidade física. Eu disse aos atores: "façam um caminhãozinho afegão!". Eles pegaram o carrinho de lixo e improvisaram. Percebemos que o espetáculo estava sobre os carrinhos e não alhures. Fabricamos diferentes carrinhos, sem nada nos perguntar. Era evidente! Todos eram pedaços de teatro. Durante os ensaios, jamais eu os havia pensado assim. Aliás, não tinha tempo" (Mnouchkine, 2004a).

O material trabalhado pelo grupo, por sua autenticidade e sua carga dramática, confere ao espetáculo a potência dos melhores documentários. A força desses testemunhos é tal que a leitura em off de uma carta e a visualização de sua tradução sobre um fundo negro torna-se emocionante. Mas o espetáculo oferece mais do que isso e a trupe transmite sua mensagem humanista por meio de uma direção surpreendente, onde a precariedade e a urgência da situação em que se encontram os refugiados são reforçadas pela presença, extremamente bem sucedida, da música de Jean-Jacques Lemêtre, com sons que se sobrepõe e cuja complexidade permitiu a Mnouchkine trabalhar com maior simplicidade, visando apenas o essencial e dispensando eventuais anedotas ou comentários.

A música sempre esteve presente nos trabalhos do Soleil. Jean-Jacques Lemêtre uniu-se a Mnouchkine em 1979, quando da criação de Méphisto, e, desde então, pode-se dizer que no Soleil a música é tão importante quanto o texto. Mnouchkine liga a música ao corpo. Segundo ela, a presença da música aproxima os espectadores e serve também para amenizar a densidade e a longa duração dos espetáculos que cria. Se, por vezes, a música é o espaço, em outros momentos é o próprio destino, ou a memória, ou ainda o ritmo interno de um personagem, 
sua própria respiração. A simbiose entre música e cena pressupõe uma perfeita harmonia entre Mnouchkine e Jean-Jacques Lemêtre, como observa a encenadora:

"Jean-Jacques nunca é o mesmo. É um verdadeiro músico de teatro. Ouve a respiração de um ator. A forma como se inspira na música asiática é muito douta. Tem grande conhecimento dessas músicas, mas como nós, trata-as de uma maneira imaginária. Quando utiliza um instrumento asiático, nunca o faz de maneira tradicional. Jean-Jacques não me impõe nada, ele me permite tudo. Ele abre o imaginário. É um excelente leitor. É sem dúvida aquele que segue melhor o texto" (Mnouchkine, 2004b).

Indagada por Béatrice Piccon-Valin se durante o processo de criação existe uma hierarquia para as artes, Mnouchkine responde:

"Nosso guia é o teatro. A questão crucial é saber o que é teatro e o que não é. Música, iluminação, atores, direção, tudo bem. Mas é teatro? Existe forma e conteúdo dentro do que fazemos? Ou existe apenas forma, ou apenas conteúdo, e então o teatro não acontecerá? Para viver, é necessário ar, mas também sangue. $\mathrm{O}$ teatro não se faz sozinho. Cada coisa no teatro só adquire valor na medida em que precisamos do outro para nos exprimir" (Mnouchkine, 1995).

Le Dernier caravansérail não é nem ficção nem justaposição de teatro e realidade, mas uma teatralização do real. O espetáculo põe em cena aqueles que fogem de seu país em busca de um Eldorado sonhado e geralmente inacessível. Não se trata de uma peça, mas talvez de um objeto teatral não assinado. Uma realização coletiva. Ainda que Mnouchkine e Cixous tenham dividido a tarefa de alinhavar os relatos recolhidos, para o espetáculo mais coletivo jamais encenado depois de L'âge d'or, contribuiu a visão e a emoção de cada um dos trinta e seis atores. "É um espetáculo sobre nossa época”, diz Ariane Mnouchkine, "sobre um dos seus fenômenos cruciais".

"Uma parte do mundo quer viver alhures. Nosso século é feito disso, e isso cria alguns problemas. Há situações insuportáveis em países onde, às vezes, nossa responsabilidade está comprometida. Não sou dessas pessoas que culpam unicamente a colonização. Os autóctones também são responsáveis. Mas nós também, na medida em que não intervimos contra as tiranias. O nosso espetáculo reconstitui odisséias. Não seguimos uma multidão, seguimos indivíduos. Viajamos com eles, e muito. A unidade de lugar é o mundo. Do Pacífico ao Atlântico, da Austrália ao Canal da Mancha, via Bali e Istambul. Será também a história dos que permanecem e a daqueles que estão nos países que fazem sonhar, sem ser necessariamente países de sonho" (Mnouchkine, 2003b).

Ao afirmar que, "se pretendemos oferecer alegria a mil pessoas ao mesmo tempo durante duas ou três horas, temos que falar de vida, de percurso humano, de indivíduos. Nada de idéias frias. Eu me comunico através de emoções" (Mnouchkine, 1978). Ariane Mnouchkine preserva seu papel de artista, denunciando, resistindo e tendo como única arma sua arte, consciente e acima de tudo responsável e sem perder seu conteúdo político, pois para ela é político todo teatro digno desse nome. Fiel às suas convicções, ela conseguiu libertar dois prisioneiros dos campos australianos e hoje eles fazem parte do Théâtre du Soleil. Isso não impede que ela se sinta em dívida com os outros.

No dia da estréia de Le Dernier caravansérail, antes mesmo do impacto causado pelo espetáculo, houve uma demonstração clara da ética "mnouchkiniana" que rege o Soleil: o público, à entrada do teatro, é convidado a dirigir-se à uma pequena mesa, onde dois membros da companhia trocam os ingressos adquiridos por outros onde se lê "convite" e devolvem aos especta- 
dores o valor pago. A explicação: Mnouchkine julgava que o espetáculo não estava pronto e a estréia teria valor de ensaio geral. Quantas companhias no mundo fariam o mesmo? O Théâtre du Soleil, mais do que uma exceção dentro da exceção cultural francesa, é único no mundo.

Le Dernier caravansérail poderia ser o outro nome do Théâtre du Soleil. Afinal de contas, quantos refugiados passaram e continuam a passar pela Cartoucherie antes de conseguir uma situação regular na França, encontrando ali o abrigo negado pelos governos de tantos países? Além do mais, os 84 membros da trupe, revelando suas 35 nacionalidades e falando 22 línguas, não são o retrato do que é o mundo de hoje e a própria França?

Isso não impede Mnouchkine de reivindicar a nacionalidade francesa para o Théâtre du Soleil. "Somos um teatro francês" (Mnouchkine, 2003b). E a palavra "francês" dita por Ariane Mnouchkine soa tão forte quanto a imagem da bandeira tricolor francesa tremulando na entrada do Théâtre du Soleil, ao lado da divisa "Liberdade, igualdade, fraternidade", lembrando que, sem ser um edifício público, ali os valores da república francesa estão presentes.

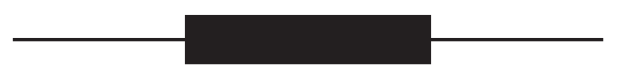

\section{Referências bibliográficas}

BELUGGI-VANNUCINI, Duccio. “Trois ans après Tambours sur la digue, la troupe d'Ariane Mnouchkine se penche sur les indésirables du monde, réfugiés en quête de l'Eldorado”. Entrevista a Gilles Costaz. Arquivos do Théâtre du Soleil.

BRADBY, D. Le théâtre français contemporain (1940-1980). Lille: Presses Universitaires de Lille, 1990.

CIXOUS, Hélène. La Ville parjure ou Le Réveil des Erinyes. Paris/Tours: Théâtre du Soleil, 1994.

COPEAU, Jacques. Appels. Paris: Gallimard, 1974.

COUTY, Daniel \& REY, Alain (eds.). Le théâtre. Paris: Larousse-Bordas, 1997.

DORT, Bernard. "Aux deux bouts de Shakespeare". In: La représentation émancipée. Paris: Actes Sud, 1988.

GORGIARD, Ronan. "Sarkaw, le comédien kurde s'est fait une place au Soleil". Ouest France, 5 de maio de 2004.

KOURILSKY, Françoise. “De 1789 à 1793, entretien avec Ariane Mnouchkine”. In: Différent. Le Théâtre du Soleil. Travail Théâtral, fev. de 1976.

MNOUCHKINE, Ariane. "Entrevista a Gilles Costaz". Le théatre est prophétique. POLITIS, 22 de janeiro, 2004a.

. "Entrevista a Béatrice Piccon-Valin”. Arquivos do Théâtre du Soleil, fev., $2004 b$. 
MNOUCHKINE, Ariane. "Entrevista a Ronan Gorgiard". In: Sarkaw, le comédien kurde s'est fait une place au Soleil. Ouest France, 5 de maio, 2004c.

. "Entretien avec Ariane Mnouchkine". In: Les réfugiés: de la réalité au théâtre. TUBIANA, Michel \& SAVY, Nicole. Hommes et libertés, n. 124, nov.-dez., 2003 a.

- "Entrevista a Jean-Louis Perrier". In: A la Cartoucherie, les flux et les reflux de la misère et des hommes. Le Monde, 16 de janeiro, 2003b.

"Entrevista a Mona Chollet". In: Chef de troupe Ariane Mnouchkine. Le théâtre aide à se mettre dans l'histoire. Charlie Hebdo, 23 de fevereiro de 2000.

"Une ouvre d'art commune, rencontre avec le Théâtre du Soleil. Entrevista feita por Béatrice Piccon-Valin com Ariane Mnouchkine, Jean-Jacques Lemêtre, Catherine Schaub, GuyClaude François, Simon Abkarian”. Aubervilliers, Théâtre/Public, n. 124-125, jul.-out., 1995.

. "Viser la perfection pour atteindre la beauté". In: Messages des Postes et Télécommunications, fev. 1991.

. "Entrevista com Catherine Delgan". In: L'acteur est un scaphandrier de l'âme. Le Soir, 2021-22 de julho, 1984 .

"Entrevista a Gilles Costaz". In: Mnouchkine, la reine Soleil. Le Matin, 17 de janeiro, $1984 \mathrm{~b}$.

. Molière d'Ariane Mnouchkine au Gaumont. Grenoble, 9 de setembro de 1978.

. "Différent, le Théâtre du Soleil”. In: Travail Théâtral, fev. 1976.

Entrevista a Yvon Davis, Michèle Raoul-Davis e Bernard Sobel. In: L'àge d'or. Dossier texte et théâtralité. Aubervilliers, Théatre/Public, n. 5-6.

MONOD, Richard. Le Théâtre. Direção de Daniel Couty e Alain Rey. Paris: Larousse-Bordas, 1997.

MOUNIER, Catherine. "L'Âge d'or, première ébauche”. In: BABLET, Denis \& JACQUOT, Jean. Les Voies de la Création Théatrale, n. 5. Paris: CNRS, 1977.

NEUSCHAFFER, Anne. 1970-1975: Ecrire une comédie de notre temps. La filiation avec Jacques Copeau. Arquivos do Théâtre du Soleil, s./d.

PENCHENAT, Jean-Claude. "L'aventure". Le Monde, 26 de maio de 1994, dossiê especial: Le Théâtre du Soleil a 30 ans.

PERRET, Jean. "Entretien avec Ariane Mnouchkine". In: Le Théâtre du geste. Mimes et acteurs. Paris: Bordas, 1987.

SALINO, Brigitte. "Soleil voilé pour Ariane Mnouchkine”. Le Monde, 21 de outubro de 1994.

SIMON, Alfred. "Les Dieux qu'il nous faut. Entretien avec Ariane Mnouchkine”. In: Acteurs, n. 2, fev. 1982.

THÉÂTRE DU SOLEIL. 1793: la cité révolutionnaire est de ce monde. Paris: Stock (Théâtre Ouvert), 1972.

Inventer collectivement son texte. In: Les Nouvelles Littéraires, n. 2420, 11 de fevereiro de 1974. 